\title{
Lactococcus lactis subspecies lactis also causes white muscle disease in farmed giant freshwater prawns Macrobrachium rosenbergii
}

\author{
Pei-Chi Wang ${ }^{1}$, Yu-De Lin ${ }^{2}$, Li-Ling Liaw ${ }^{3}$, Red-Shiung Chern ${ }^{2, *}$, Shih-Chu Chen ${ }^{2,4, * *}$ \\ ${ }^{1}$ Department of Tropical Agriculture and International Cooperation, ${ }^{2}$ Department of Veterinary Medicine, and \\ ${ }^{4}$ Graduate Institute of Animal Vaccine Technology, National Pingtung University of Science and Technology, Pingtung 912, \\ Taiwan, ROC \\ ${ }^{3}$ Bioresource Collections and Research Center, Food Industry Research and Development Institute, Hsinchu 300, Taiwan, ROC
}

\begin{abstract}
From May to August 2001 in Taiwan, 27 farms for the giant freshwater prawn Macrobrachium rosenbergii experienced white tail disease outbreaks in animals approximately 3 to 5 mo old, with total lengths from 6 to $8 \mathrm{~cm}$. Examination of the infected prawns revealed not only previously reported Lactococcus garvieae (16 farms) but also the novel L. lactis subsp. lactis (10 farms). One farm had shrimp infected with both bacteria. In the farms with L. lactis infections, the cumulative mortality was approximately 25 to $60 \%$. Gross signs of disease were opaque and whitish muscles, while histopathology included marked edema and necrotic lesions, with inflammation in the muscles and hepatopancreas. Bacteria isolated using brain/heart infusion medium or tryptic soy agar were Gram-positive and ovoid. Eleven isolates from different farms were identified as L. lactis subsp. lactis using API 20 Strep and Rapid ID32 Strep tests and using PCR assays specific for the L. lactis subsp. lactis 16S rDNA gene (650 bp amplicon) and for the 16S to 23S rDNA interspacer region (380 bp amplicon). In addition, sequencing of the full 16S rDNA genes of 2 of the isolates (MR17 and MR26; GenBank Accession Numbers AF493058 and AF493057, respectively) revealed 99.9\% identity between the isolates and $98.7 \%$ identity to several complete 16S rRNA sequences of L. lactis subsp. lactis at GenBank. Experimental infections with our isolates gave gross signs and histopathological changes similar to those seen in naturally infected prawns. The mean lethal dose of 4 isolates and the reference strain L. lactis subsp. lactis BCRC 10791 ranged from $4.2 \times 10^{6}$ to $2.5 \times 10^{7}$ colony-forming units prawn ${ }^{-1}$, indicating virulence similar to that previously reported for $L$. garvieae. This is the first report confirming $L$. lactis subsp. lactis as a pathogen in juvenile and adult prawns from aquaculture.
\end{abstract}

KEY WORDS: Lactococcus lactis subsp. lactis - Giant freshwater prawn · Macrobrachium rosenbergii $\cdot \mathrm{PCR} \cdot 16 \mathrm{~S}$ rDNA sequencing $\cdot 16 \mathrm{~S}$ to $23 \mathrm{~S}$ rDNA interspacer regions gene

- Resale or republication not permitted without written consent of the publisher

\section{INTRODUCTION}

There are 5 species of Lactococcus: L. garvieae, L. piscium, L. lactis, L. plantarum and L. raffinolactis, of which L. lactis comprises 2 subspecies: lactis and cremoris. Only 2 out of the 5 species of Lactococcus are pathogenic for fish, namely L. garvieae and L. piscium (Williams et al. 1990, Eldar et al. 1994, 1996), and only L. garvieae are pathogenic for giant freshwater prawn Macrobrachium rosenbergii (Chen et al. 2001).
The giant freshwater prawn Macrobrachium rosenbergii is commercially farmed throughout the world and intensively in Taiwan, where production decreased by 47 to 52 \% from 1992 to 1995 as result of disease (New 1995, Taiwan Fisheries Bureau 1996). Two diseases have been linked to production decline: a yeast infection that develops primarily in the cool season (October to March) and presents a yellow exoskeleton, a swollen hepatopancreas (HP), milky he- 
molymph and opaque or whitish muscles (Shu 1993, Chen et al. 2003), and a Lactococcus garvieae infection that occurs principally in the hot season (June to September, especially during phytoplankton blooms) and causes muscle necrosis (Cheng \& Chen 1988a,b, Chen et al. 2001). Streptococcus lactis, recently reclassified as Lactococcus lactis, is not recognized as a common veterinary pathogen, but it has occasionally been reported in the etiology of cattle mastitis and in septic arthritis of the neonatal calf (Wichtel et al. 2003). L. lactis is considered to be a skin commensal, and cattle are natural hosts. Although rare, human infection with $L$. lactis was first reported by Ledger et al. (1974). It has since been reported as a cause of endocarditis (Mannion \& Rothburn 1990, Clark \& Burnie 1991), arthritis (Campbell et al. 1993) and septicemia in an immunocompromised patient (Durand et al. 1995). However, infection by L. lactis subsp. lactis in aquatic animals in aquaculture has not previously been reported. This study identified the causative bacteria of a serious disease in cultured $M$. rosenbergii in Taiwan as L. lactis subsp. lactis by Rapid ID 32 Strep, polymerase chain reaction (PCR) and 16S rDNA sequencing.

\section{MATERIALS AND METHODS}

Prawn samples. For histopathological and bacteriological analysis, 5 diseased prawns (body weight 3 to $5 \mathrm{~g}$; length 6 to $8 \mathrm{~cm}$ ) were collected from each of 27 prawn farms during outbreaks of lactococosis from May to August 2001. Losses were as high as $60 \%$ in some ponds, with an average loss of approximately $35 \%$. The prawns had been fed with commercial pellets.

Bacteriology. Diseased prawns were placed in a sealable plastic bag and then on crushed ice for 20 min. The cuticles were surface sterilized by swabbing with $70 \%$ ethanol before being cut open to reveal underlying tissues. Swabs were then taken from muscles and from the HP for streaking on tryptic soy agar (TSA), blood agar $(\mathrm{BA}=\mathrm{TSA}+5 \%$ goat blood $)$, brain/heart infusion agar (BHI) and LowensteinJensen medium (LJM). Plates were then incubated at $25^{\circ} \mathrm{C}$ for $3 \mathrm{~d}$. Single colonies were streaked on the same media to obtain pure isolates. These isolates were then identified using the API 20 Strep, Rapid ID 32 Strep (Biomerieux Sa) and conventional bacteriological tests (Chen et al. 2001).

Pathology. Muscle tissue, HP tissue and tissues of other internal organs with lesions were fixed in Davidson's fixative and processed for paraffin sectioning. Sections were stained using hematoxylin and eosin (H\&E) and Gram stains and were viewed microscopically (Chen et al. 2001).
Bacterial strains. The following bacterial strains were used as controls for PCR assays: Lactococcus garvieae (American Type Culture Collection, ATCC 43921) and L. garvieae from rainbow trout (MZ9101 [KG-] from Dr. Terutoyo Yoshida, Miyazaki University, Japan). Additionally, the following strains were obtained from the Bioresource Collection Research Center, Taiwan: Enterococcus faecalis BCRC 10066, E. durans BCRC 10790, L. lactis subsp. lactis BCRC 10791, L. lactis subsp. cremoris BCRC 11067, L. raffinolactis BCRC 14039 and E. avium BCRC 10801. Eleven purified bacterial isolates derived from infected prawns were labeled MR13, MR14, MR16, MR17, MR19, MR20, MR26, MR27, MR28, MR29 and MR36.

DNA extraction. Bacteria were grown at $25^{\circ} \mathrm{C}$ in $\mathrm{BHI}$ broth and harvested by centrifugation at $7000 \times g$ for $45 \mathrm{~min}$ at $4^{\circ} \mathrm{C}$ for nucleic acid extraction. The pelleted bacteria were then lysed with lysozyme at $30 \mathrm{mg} \mathrm{ml}^{-1}$ for $1 \mathrm{~h}$ at $37^{\circ} \mathrm{C}$, followed by the addition of SDS to $5 \%$ $(\mathrm{w} / \mathrm{v})$ for $15 \mathrm{~min}$ at $37^{\circ} \mathrm{C}$. Equal volumes of phenol/ chloroform/isoamylalcohol (25:24:1) solution were added to the lysate and gently mixed before centrifugation at $12000 \times g$ for $15 \mathrm{~min}$ at $4^{\circ} \mathrm{C}$. The supernatant layer was then collected, and DNA was precipitated by addition of $0.5 \mathrm{vol}$ of isopropanol and incubated for $30 \mathrm{~min}$ at $-20^{\circ} \mathrm{C}$, followed by centrifugation at $12000 \times g$ for $15 \mathrm{~min}$ at $4^{\circ} \mathrm{C}$. The DNA pellets were washed with $70 \%$ ethanol, dried in a Speedvac and then resuspended in $20 \mu \mathrm{l}$ of TE buffer.

PCR. Specific primers LLF (5'-GCAATTGCATCACTCAAAGA-3') and LLR (5'-ACAGAGAACTTATAGCTCCC-3') were designed from diagnostic regions of the Lactococcus lactis subsp. lactis 16S rRNA gene sequence (Accession Number M58837; Goyache et al. 2001). The PCR amplifications were performed in a $100 \mu \mathrm{l}$ reaction volume containing $150 \mathrm{ng}$ of each primer, $1 \mathrm{mM}$ of each deoxynucleoside triphosphate, $1 \mathrm{U}$ of Taq DNA polymerase (Takara) and $25 \mathrm{ng}$ of template DNA in $1 \times$ reaction buffer. The following conditions were used for amplification: initial denaturation at $94^{\circ} \mathrm{C}$ for $2 \mathrm{~min}$, followed by 30 cycles of denaturation for $1 \mathrm{~min}$ at $92^{\circ} \mathrm{C}$, annealing for $1.5 \mathrm{~min}$ at $50^{\circ} \mathrm{C}$ and extension for 2 min at $72^{\circ} \mathrm{C}$, with final extension for 5 min at $72^{\circ} \mathrm{C}$. All L. lactis subsp. lactis prawn isolates produced the expected PCR amplification product of $650 \mathrm{bp}$. No amplification was observed with any other Lactococcus species tested, indicating the specificity of the PCR assay.

Amplification of $16 \mathrm{~S}$ to $23 \mathrm{~S}$ rDNA spacer regions. Synthetic oligonucleotide primers developed by Jensen et al. (1993) (G1: 5'-GAAGTCGTAACAAGG-3'; L1: 5'-CAAGGCATCCACCGT-3') were employed to amplify the $16 \mathrm{~S}$ to $23 \mathrm{~S}$ rDNA intergenic spacer region. This produced a $430 \mathrm{bp}$ amplicon for Lactococcus garvieae and a $380 \mathrm{bp}$ amplicon for L. lactis subsp. lac- 
tis (Blaiotta et al. 2002). Amplification conditions consisted of an initial denaturation step at $94^{\circ} \mathrm{C}$ for $1 \mathrm{~min}$, followed by 35 cycles of denaturation at $94^{\circ} \mathrm{C}$ for $1 \mathrm{~min}$, annealing at $55^{\circ} \mathrm{C}$ for $2 \mathrm{~min}$ and extension at $72^{\circ} \mathrm{C}$ for $3 \mathrm{~min}$, with final extension at $72^{\circ} \mathrm{C}$ for $10 \mathrm{~min}$. The PCR products $(5 \mu \mathrm{l})$ were subjected to electrophoresis $(35 \mathrm{~min}, 100 \mathrm{~V}$ ) in $2 \%$ agarose gel (SeaKem LE agarose) with $1 \times$ TBE buffer (BDH Laboratory Supplies) containing $90 \mathrm{mM}$ Tris, $90 \mathrm{mM}$ borate and $2 \mathrm{mM}$ EDTA $(\mathrm{pH}$ 8.3) and were visualized by ethidium-bromide staining. The DNA molecular weight marker comprised a 100 bp ladder (100 bp ET marker; Chenig Hsin Tang Chemical Company).

16S rDNA sequencing. Amplification of $16 \mathrm{~S}$ rDNA was by PCR using purified DNA and a primer combination consisting of forward primer 5F (5'-TGGAGAGTTTCCTGGCTCAG-3') and reverse primer 1540R (5'AAGGAGGTGATCCARCCGCA-3'). The amplification protocol was initial denaturation for $10 \mathrm{~min}$ at $95^{\circ} \mathrm{C}$, followed by 30 cycles of denaturation for $30 \mathrm{~s}$ at $95^{\circ} \mathrm{C}$, annealing for $30 \mathrm{~s}$ at $60^{\circ} \mathrm{C}$ and extension for $45 \mathrm{~s}$ at $72^{\circ} \mathrm{C}$, with final extension for $10 \mathrm{~min}$ at $72^{\circ} \mathrm{C}$. The PCR products were purified with a QIAquick PCR purification kit (Qiagen). Sequencing of the 16S rDNA PCR fragment from strains MR17 and MR26 was performed using a MicroSeq 16S rRNA Gene Kit (Applied Biosystems). The manufacturer's recommended protocols were followed. The purified sequencing reaction mixtures were automatically electrophoresed using an Applied Biosystems Model 310 automatic DNA sequencer. The final sequences of MR17 and MR28 were determined from overlapping sequence data using MicroSeq software (Applied Biosystems). The resultant 16S rDNA sequences were manually aligned with sequences of representative strains retrieved from GenBank, DDBJ and EMBL databases.

Experimental infections. Healthy prawns (Macrobrachium rosenbergii: body weight 3 to $4 \mathrm{~g}$; length 6 to $8 \mathrm{~g}$ ) were obtained from prawn farms in Pingtung, Taiwan, and held at a density of 100 prawns in continuously aerated $400 \mathrm{l}$ aquaria containing $300 \mathrm{l}$ of freshwater at approximately $27^{\circ} \mathrm{C}$ for $7 \mathrm{~d}$ until they were acclimatized to laboratory conditions. They were fed twice daily with commercial prawn pellets, and waste was removed daily. Subsequently, 280 prawns of uniform size were selected for challenge tests using 5 strains of Lactococcus lactis subsp. lactis (MR13, MR17, MR26, MR28 and BCRC 10791). For challenge with each strain, 56 prawns were subdivided into 8 groups of 7 prawns each. Bacterial suspensions at an optical density of 1.0 (absorbance at $610 \mathrm{~nm}$ ), equal to a viable bacterial count of $10^{9}$ colony-forming units (cfu) per milliliter, were successively diluted 10 -fold in sterile $\left(121^{\circ} \mathrm{C}, 15 \mathrm{~min}\right)$ normal saline to obtain a range of $1.2 \times 10^{9}$ to $1.2 \times 10^{3} \mathrm{cfu} \mathrm{ml}^{-1}$ (validated by standard plate counts). For each of 7 dilutions for each strain, $0.1 \mathrm{ml}$ bacterial solution was injected intramuscularly (IM) into 7 prawns. Sterile normal saline $(0.1 \mathrm{ml})$ was injected IM into 7 prawns of Control Group 8. After injection, each group was incubated separately in an 801 aquarium under the same conditions as described for the acclimatization period. The prawns were continuously monitored for morbidity and mortality and were sampled for histopathological and bacteriological analyses.

\section{RESULTS}

\section{Clinical signs, bacteriology and histopathology}

All moribund prawns Macrobrachium rosenbergii from different prawn farms exhibited poor growth and a whitish body color. Gross pathological changes were whitish muscles and a swollen, yellowish HP. Smears from fresh HP, muscle tissue and tissues of other internal organs of diseased prawns showed the presence of numerous cocci ranging from 0.1 to $0.3 \mu \mathrm{m}$ in diameter. Bacterial colonies from the muscle and hepatopancreas appeared 1 to $2 \mathrm{~d}$ after culture on the TSA, BA and BHI. Colonies were evident after $24 \mathrm{~h}$ incubation on BHA agar and were roughly the size of a pin head. They were semitransparent and grew larger (0.05 to $0.1 \mathrm{~cm}$ in diameter) after $48 \mathrm{~h}$ incubation. The bacteria were Gram positive and were typical cocci $(0.1$ to $0.3 \mu \mathrm{m})$.

Histopathologically, edematous fluid in moribund prawns accumulated between the cuticle and muscle, and large numbers of hemocytes infiltrated the subcuticular area, epidermis and dermis. Abdominal, pereiopod and pleopod muscles showed substantial edema and liquefactive necrosis, with large numbers of bacterial cells. Diseased prawns showed marked edematous fluid accumulation between the cuticle and underlying muscle tissue, and there was fragmentation of muscle bundles with liquefactive necrosis. Large numbers of cocci were identified in muscles of the abdomen, pereiopods and pleopods (Fig. 1). Necrotizing foci encapsulated by hemocytes (granulomas) also developed in the muscle. Fibrous tissues were also identified in the muscle. Sloughed HP tubular epithelial cells appeared in tubular lumens, and necrotizing foci with bacterial clumps and inflammation were found in interstitial spaces (Fig. 2). Sloughed HP tubular epithelial cells and bacteria formed mixed debris in tubule lumens of some prawns. Necrotic foci and bacterial clumps were also detected in the heart, stomach and other organs.

All 135 diseased prawns (i.e. 5 prawns collected from each of 27 farms) yielded bacterial colonies on agar 


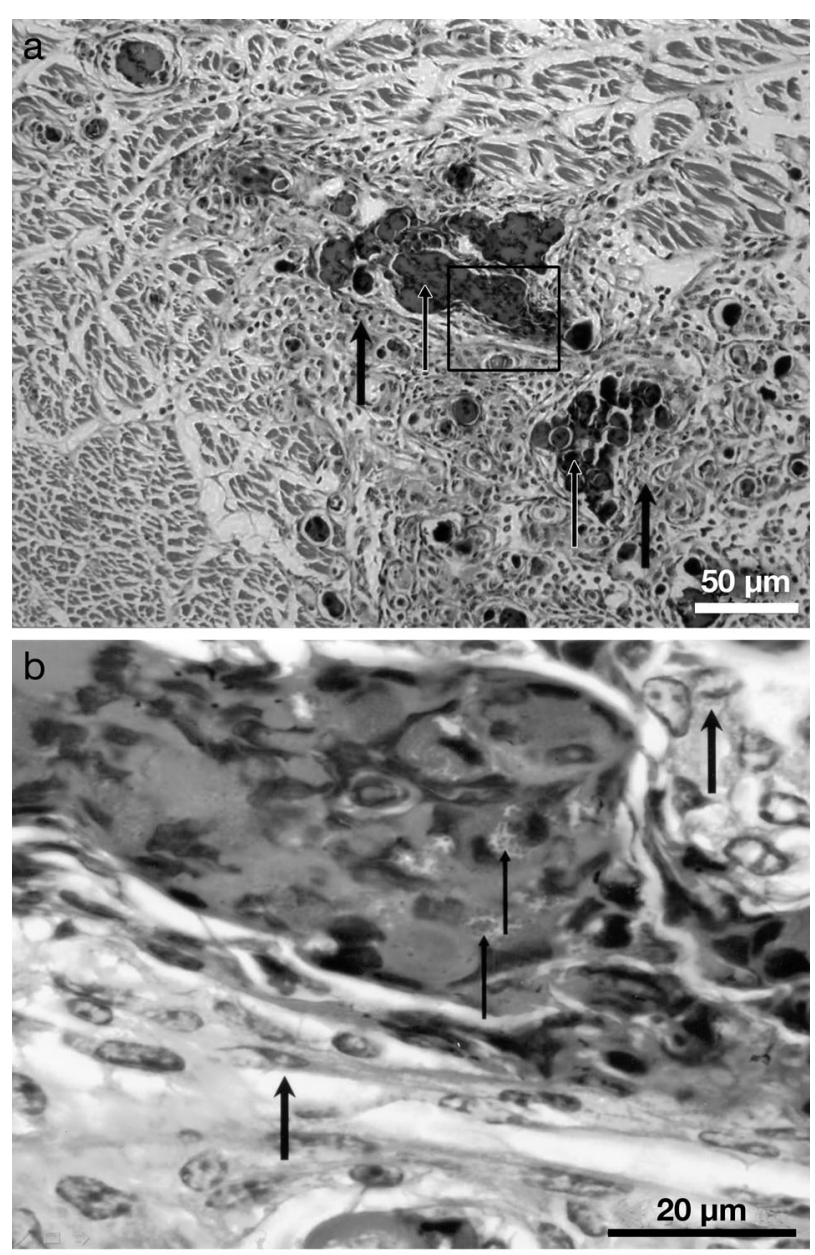

Fig. 1. Macrobrachium rosenbergii. (a) Giant freshwater prawn tissue section showing markedly necrotized foci with cellular debris (small arrows) surrounded by fibrous tissue and hemocytes (large arrows) as a granuloma in the muscle tissues. (b) Inset from (a), showing bacterial clumps (small arrows) and fibrous tissue (large arrows) in a granuloma (H\&E)

plates. One colony was selected from each prawn for PCR followed by sequencing. This revealed that prawns from 10 farms (50 prawns) were infected with Lactococcus lactis subsp. lactis, while those from 16 farms (80 prawns) were infected with L. garvieae. At the remaining farm, 3 of the prawns were infected with L. garvieae and 2 with $L$. lactis subsp. lactis. Thus, the prevalence for L. garvieae and L. lactis subsp. lactis infections was $61.5 \%$ (83/135) and 38.5\% (52/135), respectively. Since it was not possible to carry out detailed biochemical analysis of bacteria from all diseased prawns, 11 isolates of L. lactis subsp. lactis (1 prawn isolate from each farm labeled as MR13, MR14, MR16, MR17, MR19, MR20, MR26, MR27, MR28, MR29 and MR36) were selected for detailed biochemical and physiological tests and for comparison with reference strains of L. lactis subsp. lactis BCRC 10791, L.
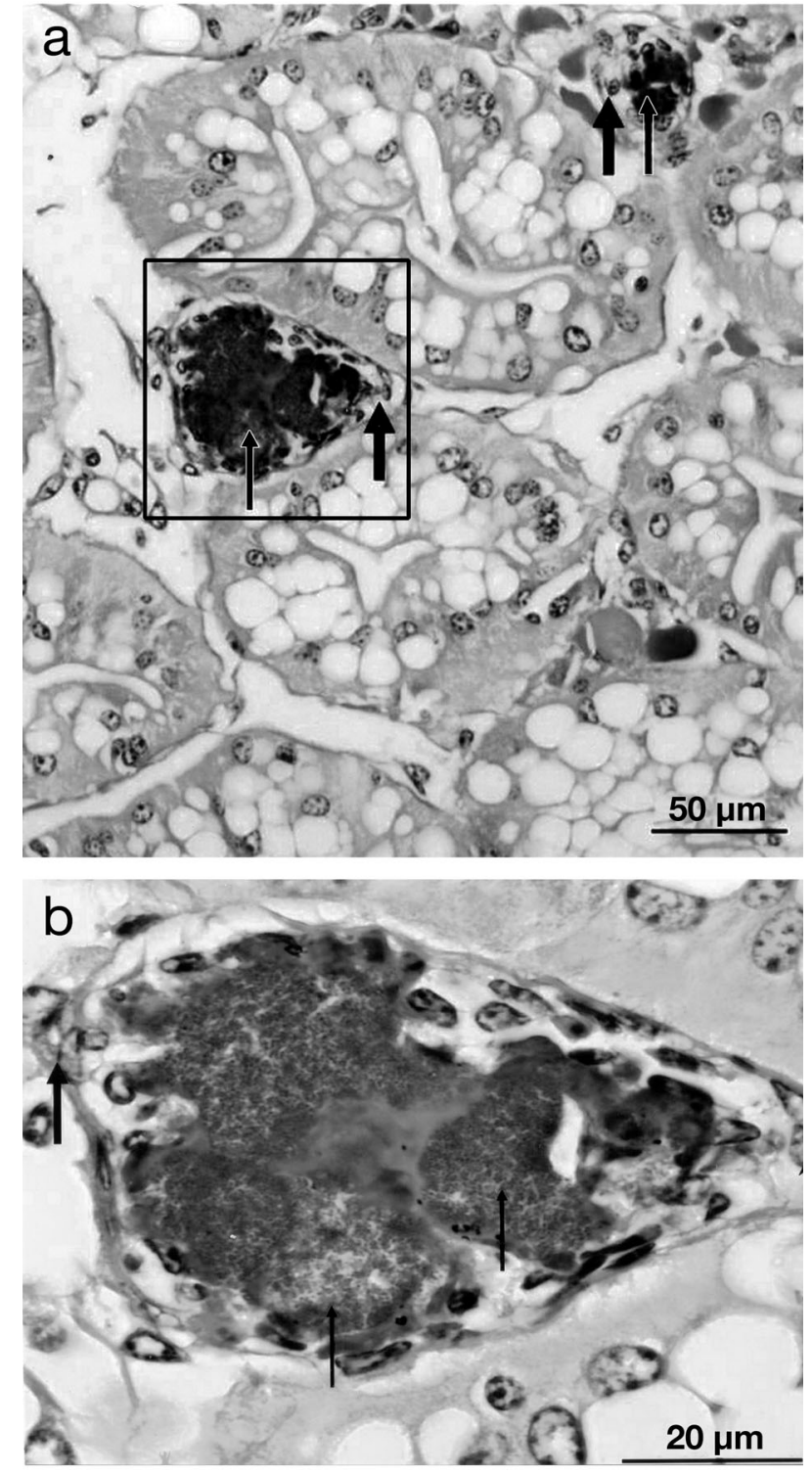

Fig. 2. Macrobrachium rosenbergii. (a) Giant freshwater prawn section showing necrotized foci in the hepatopancreas with cellular debris (small arrows) surrounded by hemocytes (arrows) (H\&E). (b) Inset from (a), and showing bacterial clumps (small arrows) and hemocytes (large arrows) (Gram stain, 1000×)

lactis subsp. cremoris BCRC 11067 and L. garvieae ATCC 43921.

Table 1 shows the results of biochemical and physiological characteristics using API 20 Strep tests for our 11 isolates from diseased Macrobrachium rosenbergii (MR13, MR14, MR16, MR17, MR19, MR20, MR26, MR27, MR28, MR29 and MR36) and for the reference strains. Results for our 11 isolates are summarized in Column 1 of the table. All 11 isolates were Gram-positive cocci that showed $\gamma$ hemolysis on blood agar, but did not grow in $6.5 \% \mathrm{NaCl}$. All grew over a wide tem- 
Table 1. Macrobrachium rosenbergii. Biochemical characteristics of bacterial isolates from diseased M. rosenbergii compared to the characteristics of reference strains. Column 1 summarizes test results for our 11 test isolates, where a single symbol indicates a uniform positive $(+)$ or negative $(-)$ test result and fractions indicate the number of isolates that gave positive results over the number that gave negative results. ATCC: American Type Culture Center; BCRC: Bioresource Collection Research Center, Taiwan; LLSL: Lactococcus lactis subsp. lactis BCRC 10791; LLSC: L. lactis subsp. cremoris BCRC 11067; LR: L. raffinolactis BCRC 14039; LG1: L. garvieae from rainbow trout (MZ 9101 [KG-] from Dr. T. Yoshida, Japan); LG: L. garvieae ATCC 43921; EA: Enterococcus avium BCRC 10801; ED: E. durans BCRC 10790; EF: E. faecalis BCRC 10066

\begin{tabular}{|c|c|c|c|c|c|c|c|c|c|}
\hline API 20 Strep test & Test & LLSL & LLSC & LR & LG1 & LG & EA & ED & $\mathrm{EF}$ \\
\hline Pyruvate & + & + & + & + & + & + & + & + & + \\
\hline Hippurate & - & - & - & - & - & - & - & - & - \\
\hline Esculin & + & + & + & + & + & + & + & + & + \\
\hline Pyrrolldonyl 2-naphthylamide & + & + & - & - & + & + & + & + & + \\
\hline$\beta$-bromo-2-naphthyl- $\alpha$-D-galactopyranoside & - & - & - & + & - & - & - & + & - \\
\hline Naphthol-AS-BI- $\beta$-D-glucuronate & - & - & - & - & - & - & - & - & - \\
\hline 2-naphthyl- $\beta$-D-D-galactopyranoside & - & - & + & - & - & - & - & + & + \\
\hline 2-naphthyl phosphate & - & - & - & - & - & - & - & - & - \\
\hline L-leucine-2-naphthylamide & $4 / 7$ & + & + & + & + & + & - & - & + \\
\hline Arginine & $9 / 2$ & + & + & - & + & + & - & + & + \\
\hline Ribose & $4 / 7$ & + & + & - & + & + & + & + & + \\
\hline L-arabinose & - & - & - & - & - & - & + & - & - \\
\hline Mannose & $3 / 8$ & - & - & - & + & + & + & - & + \\
\hline Sorbital & - & - & - & - & - & - & + & - & + \\
\hline Lactose & $3 / 8$ & - & - & + & - & - & + & + & + \\
\hline Trehalose & $8 / 3$ & + & + & + & + & + & + & - & + \\
\hline Inulin & $7 / 4$ & - & - & - & - & - & + & - & - \\
\hline Raffinose & - & - & - & + & - & - & + & - & - \\
\hline Starch & $4 / 7$ & + & - & + & + & - & + & + & + \\
\hline Glycogen & - & - & - & - & - & - & - & - & - \\
\hline Hemolysis (goat RBC) & $\gamma$ & $\gamma$ & $\gamma$ & $\gamma$ & $\alpha$ & $\alpha$ & $\alpha$ & $\alpha$ & $\gamma$ \\
\hline pH 9.6 & + & + & + & - & + & + & + & + & + \\
\hline \multicolumn{10}{|l|}{ Tolerance at: } \\
\hline $6.0 \% \mathrm{NaCl}$ & + & + & + & - & + & + & + & + & + \\
\hline $6.5 \% \mathrm{NaCl}$ & - & - & + & - & + & + & + & - & + \\
\hline $8.0 \% \mathrm{NaCl}$ & - & - & - & - & + & - & - & - & + \\
\hline $10 \% \mathrm{NaCl}$ & - & - & - & - & - & - & - & - & - \\
\hline \multicolumn{10}{|l|}{ Growth at: } \\
\hline $4^{\circ} \mathrm{C}$ & + & + & + & + & + & + & + & + & + \\
\hline $40^{\circ} \mathrm{C}$ & + & + & + & + & + & + & + & + & + \\
\hline $45^{\circ} \mathrm{C}$ & $5 / 6$ & - & - & - & + & + & + & + & + \\
\hline
\end{tabular}

perature range $\left(4\right.$ to $\left.40^{\circ} \mathrm{C}\right)$ and in media at $\mathrm{pH} 9.6$ $\left(25^{\circ} \mathrm{C}\right)$. All exhibited negative reactions for hippurate, $\beta$-bromo-2-naphthyl- $\alpha$-D-galactopyranoside, naphtholAS-BI- $\beta$-D-glucuronate, 2 -naphthyl- $\beta$-D-D-galactopyranoside, 2-naphthyl phosphate, L-arabinose, sorbital, raffinose and glycogen, but a positive reaction for pyruvate, esculin and pyrrolldonyl 2-naphthylamide. The characteristics of the 11 isolates were generally similar to those of Lactococcus lactis subsp. lactis. Exceptions were minor differences in some assimilation tests for some isolates. According to the morphology and the physiological and biochemical test results, the 11 strains isolated from $M$. rosenbergii would be classified in the genus Lactococcus. However, based on the biochemical tests results for API 20 Strep alone, it was difficult to conclude whether these isolates were conspecific with L. lactis subsp. lactis.
In further tests of our 11 isolates using a commercial ATB expression system (Rapid ID 32 Strep, bioMerieux), scores of good to very good identification (96.3 to $99.8 \%$ ) for Lactococcus lactis subsp. lactis were obtained (Table 2). With the same test system, excellent identification $(99.9 \%$ ) was obtained for reference strain BCRC 10791 (Table 2).

\section{Polymerase chain reaction assay results}

PCR assay for Lactococcus lactis subsp. lactis revealed that all 11 of our isolates and the reference strain L. lactis subsp. lactis BCRC 10791 gave the expected amplicon of $650 \mathrm{bp}$ for the L. lactis subsp. lactis 16S rDNA gene (Goyache et al. 2001) (Fig. 3). PCR assays with DNA extracts from other bacteria, 
including L. lactis subsp. cremoris BCRC 11067, Enterococcus durans BCRC 10790, L. raffinolactis BCRC 14039 and E. avium BCRC 10801, L. garvieae ATCC 43921 and L. garvieae MZ9101 gave no amplicons (data not shown for the latter 2 strains). When the PCR assay was performed with 10 -fold dilutions of isolate MR26, the $650 \mathrm{bp}$ amplicon was obtained with a dilution corresponding to 20 bacterial cells $(20 \mathrm{cfu}$, data not shown).

Primers G1 and L1 specific for the 16S to 23S rDNA intergenic spacer region of Lactococcus lactis subsp. lactis gave the expected $380 \mathrm{bp}$ amplicon, with all 11 of our isolates and the reference strain L. lactis subsp. lactis BCRC 10791. No amplicons were obtained using L. lactis subsp. cremoris BCRC 11067, L. raffinolactis BCRC 14039, Enterococcus avium BCRC 10801, or E. durans BCRC 10790 (Fig. 4).

Table 2. Macrobrachium rosenbergii. Rapid ID 32 Strep system characteristics of the Lactococcus lactis strains isolated from diseased $M$. rosenbergii in comparison to the reference strains of the Lactococcus group. Column 1 summarizes test results for our 11 test isolates, where a single symbol indicates a uniform positive $(+)$ or negative $(-)$ test result and fractions indicate the number of isolates that gave positive results over the number that gave negative results. See Table 1 legend for reference isolate names

\begin{tabular}{|c|c|c|c|c|}
\hline Rapid ID 32 Strep test & Test & LLSL & LLSC & LG \\
\hline Arginine dihydrolase & + & + & + & + \\
\hline$\beta$-glucosidase & + & + & + & + \\
\hline$\beta$-galactosidase & - & - & - & - \\
\hline$\beta$-glucuronidase & - & - & - & - \\
\hline$\alpha$-galactosidase & - & - & - & - \\
\hline Alkaline phosphatase & - & - & - & - \\
\hline Ribose & - & + & - & - \\
\hline Mannitol & + & - & + & - \\
\hline Sorbitol & - & - & - & - \\
\hline Lactose & + & + & + & - \\
\hline Trehalose & + & + & + & + \\
\hline Raffinose & - & - & - & - \\
\hline Saccharose & + & + & + & - \\
\hline L-arabinose & + & - & + & - \\
\hline D-arabitol & $6 / 5$ & - & + & - \\
\hline Cyclodextrin & + & + & - & - \\
\hline Acetoin production & $3 / 8$ & + & - & + \\
\hline Anyl-phenylalanyl-proline arylamidase & $3 / 8$ & + & - & + \\
\hline$\beta$-galactosidase & $6 / 5$ & - & + & - \\
\hline Pyroglutamic acid arylamidase & - & - & - & - \\
\hline $\mathrm{N}$-acetyl- $\beta$-glucosaminidase & - & - & - & - \\
\hline Glycyl-tryptophan arylamidase & $9 / 2$ & - & + & - \\
\hline Hydrolysis of hippurate & $6 / 5$ & + & - & - \\
\hline Glycogen & - & - & - & - \\
\hline Pullulane & - & - & + & - \\
\hline Maltose & + & + & + & + \\
\hline Melibiose & - & - & - & - \\
\hline Melezitose & - & - & + & - \\
\hline Methyl- $\beta$-D-glucopyranoside & - & - & - & + \\
\hline Tagatose & + & - & + & - \\
\hline$\beta$-mannosidase & + & - & + & - \\
\hline Urease & - & - & - & - \\
\hline
\end{tabular}

\section{Sequencing of the 16S rDNA PCR amplicon}

Two of our isolates (MR17 and MR26) were randomly selected for sequencing of the PCR amplicon of the complete 16S rDNA gene (1542 bp). These sequences were $99.9 \%$ identical (100\% coverage) and were deposited at GenBank under Accession Numbers AF493058 and AF493057, respectively. A BLAST search against all bacteria gave top hits for 6 complete 16S rRNA sequences of Lactococcus lactis (AE006456, AE006454, AE006447, AE006443, X64887 and AY675242), all with 99\% coverage and identity ranging from 98.6 to $98.7 \%$. Also included was 1 record for the subspecies cremoris (CP000425), with 99\% coverage and $98.6 \%$ identity. By contrast, a BLAST search against complete 16S rRNA sequences for L. garvieae (3 available; L32813, AF283499 and X54262) gave coverages ranging from 90 to $94 \%$ only and identities ranging from 92.5 to $95 \%$. One of these (AF283499), with $94 \%$ coverage and $94.8 \%$ identity, was for $L$. garvieae previously isolated by our group from diseased giant freshwater prawns in Taiwan (Chen et al. 2001). One partial 16S rRNA sequence record (DQ010113) gave $98.6 \%$ identity to our sequence, but with only $92 \%$ coverage. When this sequence itself was used in a BLAST search against all bacteria, it yielded top hits for complete 16S rRNA sequences of L. lactis, with $100 \%$ coverage and $100 \%$ identity. By contrast, a BLAST search restricted to complete sequences of $16 \mathrm{~S}$ rRNA genes of $L$. garvieae yielded identities ranging from 92.1 to $94.6 \%$, with coverage of only 94 to $96 \%$. The results indicated that our isolates were L. lactis and not L. garvieae and that the record for DQ010113 should probably be labeled L. lactis rather than L. garvieae.

\section{Experimental infections}

All prawns injected with $1.2 \times$ $10^{8} \mathrm{cfu}$ of Lactococcus lactis subsp. lactis isolates MR13, MR17 and MR28 died within $2 \mathrm{~d}$. All prawns injected with $1.2 \times 10^{8}$ of bacterial strain L. lactis subsp. lactis BCRC 10791 and our isolate MR26 died within $3 \mathrm{~d}$. The $\mathrm{LD}_{50}$ values for our L. lactis subsp. lactis isolates from diseased prawns and the 


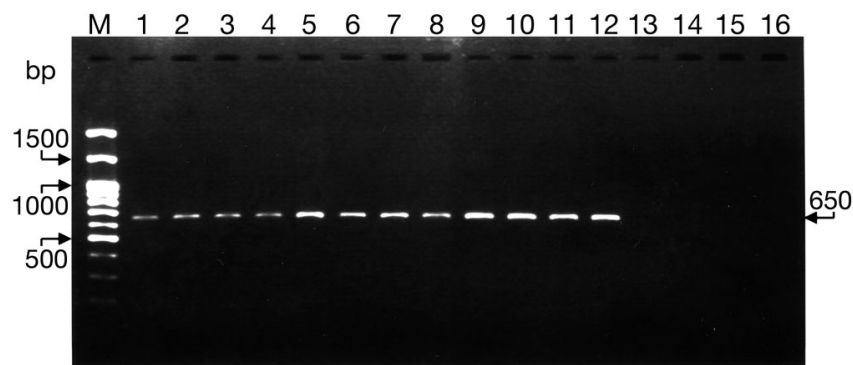

Fig. 3. Agarose gel of PCR products illustrating the specificity of the Lactococcus lactis subsp. lactis PCR assay. Lane M: DNA molecular weight marker; Lanes 1 to 11: test isolates MR13, MR14, MR16, MR17, MR19, MR20, MR26, MR27, MR28, MR29 and MR36, respectively; Lane 12: L. lactis subsp. lactis BCRC 10791; Lane 13: L. lactis subsp. cremoris BCRC 11067; Lane 14: L. raffinolactis BCRC 14039; Lane 15: Enterococcus avium BCRC 10801; Lane 16: E. durans BCRC 10790

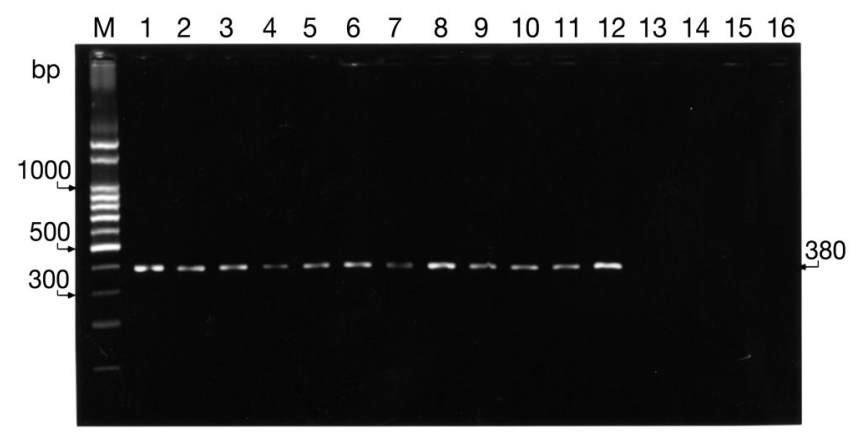

Fig. 4. Agarose gel of PCR products illustrating the specificity of the PCR assay for the 16S to 23S rDNA intergenic spacer region for Lactococcus lactis subsp. lactis. Lane identities as in Fig. 3 legend

reference strain ranged from $10^{6}$ to $10^{7} \mathrm{cfu} \mathrm{g}^{-1}$ body weight. The $\mathrm{LD}_{50}$ values of isolates MR13, MR17, MR26 and MR28, and the reference strain L. lactis subsp. lactis BCRC 10791, were $4.2 \times 10^{6}, 2.1 \times 10^{6}, 1.2 \times 10^{7}$, $4.8 \times 10^{6}$ and $2.5 \times 10^{7} \mathrm{cfu}$ prawn $^{-1}$, respectively. White muscle and histopathological changes similar to those in naturally infected prawns were observed. Pure cultures of bacteria were re-isolated from the HP and muscle of moribund prawns after bacterial challenge, and no lesions developed in the control group.

\section{DISCUSSION}

Our previous reports described Enterococcus-like (Cheng \& Chen 1998a) infections and Lactococcus garvieae (Chen et al. 2001) infections from Macrobrachium rosenbergii with similar histopathology to those described herein. However, there were also some differences. In the current study and in our previous studies with L. garvieae (Chen et al. 2001), marked necrotic areas with edematous fluid, bacterial clumps and granulomas were detected in several organs such as the gills, heart, stomach and intestine, in addition to in the muscles and HP. However, the only organs described as infected in the study by Cheng \& Chen (1998a) were the muscles and HP. The reasons for the differences are unclear, but may relate to differences in bacterial strains or rearing conditions. L. lactis subsp. lactis also caused chronic granulomatous lesions in the giant freshwater prawn similar to those seen with $L$. garvieae infection in the grey mullet (Chen et al. 2002).

The characteristics of the bacterial isolates from diseased prawns were generally similar to those of Lactococcus lactis subsp. lactis, with the exception of minor differences in some assimilation tests for some isolates only. According to morphology and physiological and biochemical test results, the 11 strains isolated from Macrobrachium rosenbergii would be classified in the genus Lactococcus. The biochemical and physiological characteristics of our 11 isolates were similar to those previously reported for L. lactis subsp. lactis by Facklam \& Elliott (1995). For instance, the exhibited 100\% positive results for trehalose and $100 \%$ negative results for hippurate, sorbitol and raffinose. However, based on the biochemical tests of the API 20 Strep kit alone, it was difficult to conclude whether the isolates were conspecific with L. lactis subsp. lactis. Because this API 20 Strep system is widely used in many clinical microbiology laboratories for the identification of Gram-positive cocci, this system should be updated or modified to improve its proficiency in identifying this as well as other emerging pathogens. On the other hand, our isolates were correctly identified as L. lactis subsp. lactis with the Rapid ID 32 Strep kit (bioMerieux).

Until recently, Lactococcus garvieae and L. lactis subsp. lactis were considered opportunistic pathogens. They are often misidentified as entercocci or streptococci, and elucidation of their clinical significance has likely been hindered by the difficulties in correct identification. However, the number of clinical cases associated with infections by L. lactis and L. garvieae has increased in the last decade in both humans and animals (Clark \& Burnie 1991, Campell et al. 1993, James et al. 2000, Wichtel et al. 2003).

Lactococcus lactis subsp. lactis, L. piscium and L. garvieae are recognized as the species with clinical significance for human and veterinary medicine. In humans, L. garvieae and L. lactis subsp. lactis have been identified in clinical samples of blood (Wang et al. 2007), skin lesions and urine. L. garvieae and $L$. picium are pathogenic for various fish species. However, infection by L. lactis subsp. lactis in cultured prawns has not previously been reported.

Although physiological tests, differences in antimicrobial susceptibility, whole-cell protein, and DNA 
or RNA analysis have been proposed to distinguish between Lactococcus lactis subsp. lactis and L. garvieae (Elliott et al. 1991, Elliott \& Facklam 1996), some of these techniques are not reliable and may be too time consuming, limiting their use for routine identification. We found that rapid PCR amplification of the $16 \mathrm{~S}$ to $23 \mathrm{~S}$ rDNA spacer region could differentiate well between L. garvieae (430 bp amplicon) and our L. lactis subsp. lactis isolates (380 bp amplicon) (Jensen et al. 1993). PCR amplification, sequencing and sequence comparison of the complete 16S rDNA from 2 of our isolates gave strong support to the argument that they and the reference strain BCRC 10791 are isolates of a single subspecies, L. lactis subsp. lactis.

BLAST searches using our AF493057 and AF493058 sequences revealed 1 anomalous identity match of $98 \%$ with DQ010113 (92\% coverage) that is listed at GenBank as a partial sequence of 16S rRNA of Lactococcus garvieae isolated from flounder. However, using DQ010113 as the query for a BLAST search against all bacteria, yielded only L. lactis records with $100 \%$ identity and $100 \%$ coverage, while a search limited to L. garvieae gave a maximum identity of $94.8 \%$ with only $94 \%$ coverage (L32813). Higher coverage (96\%) for record X54262 yielded a lower identity of $92.1 \%$. Altogether, the results suggest that DQ101113 is a sequence from the rRNA gene of L. lactis and that the originating bacterium isolated from flounder was mis-identified as L. garvieae.

White muscle disease is a major problem for giant freshwater prawn Macrobrachium rosenbergii farmers in the summer in Taiwan. Our results from both field specimens and experimental infections provide the first confirmation that Lactococcus lactis subsp. lactis infection can cause such disease outbreaks in addition to L. garvieae. Challenge tests with our field isolates and the reference strain BCRC 10791 revealed that $L$. lactis subsp. lactis has virulence for the freshwater prawn similar to that of L. garvieae (Chen et al. 2001).

Epidemiological studies suggest that white muscle disease caused by bacteria is most prevalent during the summer, peaking in June to August, and that it does not occur during the winter. No differences have been observed in water quality between ponds with diseased and healthy prawns. However, a surprisingly strong positive correlation exists between the percentage of infected prawns and high water temperature. Since we isolated only Lactococcus lactis subsp. lactis from disease outbreaks at 10 farms and only $L$. garvieae from disease outbreaks at 16 other farms, we may conclude that both bacterial species are significant causes of white muscle disease. Thus, in areas with a history of outbreaks of white muscle disease, frequent monitoring of prawns for these 2 bacterial species would be prudent during the summer.
Acknowledgements. This work was supported by National Science Council Grants NSC91-2313-B-020-028 and NSC922313-B-020017, Taiwan, ROC.

\section{LITERATURE CITED}

Blaiotta G, Pepe O, Mauriello G, Villani F, Andolfi R, Moschetti G (2002) 16S-23S rDNA intergenic spacer region polymorphism of Lactococcus garvieae, Lactococcus raffinolactis and Lactococcus lactis as revealed by PCR and nucleotide sequence analysis. Syst Appl Microbiol 25: 520-527

Campbell P, Dealler S, Lawton JO (1993) Septic arthritis and unpasteurised milk. J Clin Pathol 46:1057-1058

Chen SC, Lin YD, Liaw LL, Wang PC (2001) Lactococcus garvieae infection in the giant freshwater prawn Macrobrachium rosenbergii confirmed by polymerase chain reaction and 16S rDNA sequencing. Dis Aquat Org 45: $45-52$

Chen SC, Liaw LL, Su HY, Ko SC and others (2002) Lactococcus garvieae, a bacterial infection in grey mullet, Mugil cephalus. J Fish Dis 25:727-732

Chen SC, Chen TH, Wang PC, Chen YC and others (2003) Metschnikowia bicuspidata and Enterococcus faecium coinfection in the giant freshwater prawn Macrobrachium rosenbergii. Dis Aquat Org 55:161-167

Cheng W, Chen JC (1998a) Isolation and characterization of an Enterococcus-like bacterium causing muscle necrosis and mortality in Macrobrachium rosenbergii in Taiwan. Dis Aquat Org 34:93-101

Cheng W, Chen JC (1998b) Enterococcus-like infections in Macrobrachium rosenbergii are exacerbated by high $\mathrm{pH}$ and temperature but reduced by low salinity. Dis Aquat Org 34:103-108

Clark I, Burnie JP (1991) Immunoblotting and culture positive endocarditis. J Clin Pathol 44:152-156

Durand JM, Rousseau MC, Gandois JM, Kaplanski G, Mallet MN, Soubeyrand J (1995) Streptococcus lactis septicemia in a patient with chronic lymphocytic leukemia. Am J Hematol 50:64-65

Eldar AC, Bejerano Y, Bercovier H (1994) Streptococcus shiloi and Streptococcus difficile: two new streptococcal species causing a meningoencephalitis in fish. Curr Microbiol 28: $139-143$

Eldar AC, Ghittino C, Asanta L, Bvozzettz E, Goria M (1996) Enterococcus seriolicida is a junior synonym of Lactococcus garvieae, a causative agent of septicemia and meningoencephalitis in fish. Curr Microbiol 32:85-88

Elliott JA, Facklam RR (1996) Antimicrobial susceptibilities of Lactococcus lactis and Lactococcus garvieae by human by comparison of whole cell protein patterns. J Clin Microbiol 34:1296-1298

Elliott JA, Collins MD, Pigott NE, Facklam RR (1991) Differentiation of Lactococcus lactis and Lactococcus garvieae from humans by comparison of whole-cell protein patterns. J Clin Microbiol 29:2731-2734

Facklam RR, Elliott JA (1995) Identification, classification, and clinical relevance of catalase-negative, gram-positive cocci, excluding the streptococci and enterococci. J Clin Microbiol 8:479-495

Goyache J, Vela AI, Gibello A, Blanco MM and others (2001) Lactococcus lactis subsp. lactis infection in waterfowl: first confirmation in animals. Emerg Infect Dis 7:884-886

James PR, Hardman SM, Patterson DL (2000) Osteomyelitis and possible endocarditis secondary to Lactococcus garvieae: a first case report. Postgrad Med J 76:301-303 
Jensen MA, Webster JA, Straus N (1993) Rapid identification of bacteria on the basis of polymerase chain reactionamplified ribosomal DNA spacer polymorphisms. Appl Environ Microbiol 59(4):945-952

Ledger WJ, Kriewall TJ, Sweet RL, Fekety FR (1974) The use of parental clindamycin in the treatment of obstetricgynecologic patients with severe infections. A comparison of a clindamycin-kanamycin combination with penicillinkanamycin. Obstet Gynecol 43:490-497

Mannion PT, Rothburn MM (1990) Diagnosis of bacterial endocarditis caused by Streptococcus lactis and assisted by immunoblotting of serum antibodies. J Infect 21:317-318

Murray BB (1990) The life and times of the Enterococcus. Clin Microbiol Rev 3:46-65

New MB (1995) Status of freshwater prawn farming: a review. Aquacult Res 26:1-54

Editorial responsibility: Timothy Flegel, Bangkok, Thailand
Shu JP (1993) Studies on yeast infection in cultured giant freshwater prawn (Macrobranchium rosenbergii). MS thesis, Veterinary Dept, Chung-Hsing University, Taichung

Taiwan Fisheries Bureau (1996) Fisheries yearbook Taiwan area 1994. Taipei

Wang CYC, Shie HS, Chen SC, Huang JP and others (2007) Lactococcus garvieae infections in humans: possible association with aquaculture outbreaks. Int J Clin Pract 61: 68-73

Wichtel ME, Fenwick SG, Hunter J, Stephenson A, Martin D, Wichtel JJ (2003) Septicaemia and septic arthritis in a neonatal calf caused by Lactococcus lactis. Vet Rec 153: $22-23$

Williams AM, Fryer JL, Collins MD (1990) Lactococcus piscium sp. nov. a new Lactococcus species from salmonid fish. FEMS Microbiol Lett 56:109-113

Submitted: April 28, 2005; Accepted: September 1, 2007 Proofs received from author(s): February 12, 2008 